Jose M. Carnate, Jr., MD

'Department of Pathology

College of Medicine

University of the Philippines Manila

Correspondence: Dr. Jose M. Carnate, Jr.

Department of Pathology

College of Medicine

University of the Philippines Manila

547 Pedro Gil St. Ermita, Manila 1000

Philippines

Phone (632) 85264450

Telefax (632) 84003638

Email:jmcjpath@gmail.com

The author declared that this represents original material that is not being considered for publication or has not been published or accepted for publication elsewhere, in full or in part, in print or electronic media; that the manuscript has been read and approved by the author, that the requirements for authorship have been met by the author, and that the author believes that the manuscript represents honest work.

Disclosures: The author signed a disclosure that there are no financial or other (including personal) relationships, intellectual passion, political or religious beliefs, and institutional affiliations that might lead to a conflict of interest.

\section{(c) (1) $\odot \Theta$}

\title{
Odontogenic Keratocyst
}

A 37-year-old woman consulted for a slow-growing mass of one-year duration on the left side of the mandible with associated tooth mobility. Clinical examination showed buccal expansion along the left hemi-mandible from the mid-body to the molar-ramus region with associated mobility and displacement of the pre-molar and molar teeth. Radiographs showed a well-defined unilocular radiolucency with root resorption of the overlying teeth. Decompression and unroofing of the cystic lesion was performed.

Received in the surgical pathology laboratory were several gray-white rubbery to focally gritty tissue fragments with an aggregate diameter of $1 \mathrm{~cm}$. Histopathologic examination shows a fibrocollagenous cyst wall lined by a fairly thin and flat stratified squamous epithelium without rete ridges. (Figure 1) The epithelium is parakeratinized with a wavy, corrugated surface while the basal layer is cuboidal and quite distinct with hyperchromatic nuclei. (Figure 2) Based on these features, we signed the case out as odontogenic keratocyst (OKC).

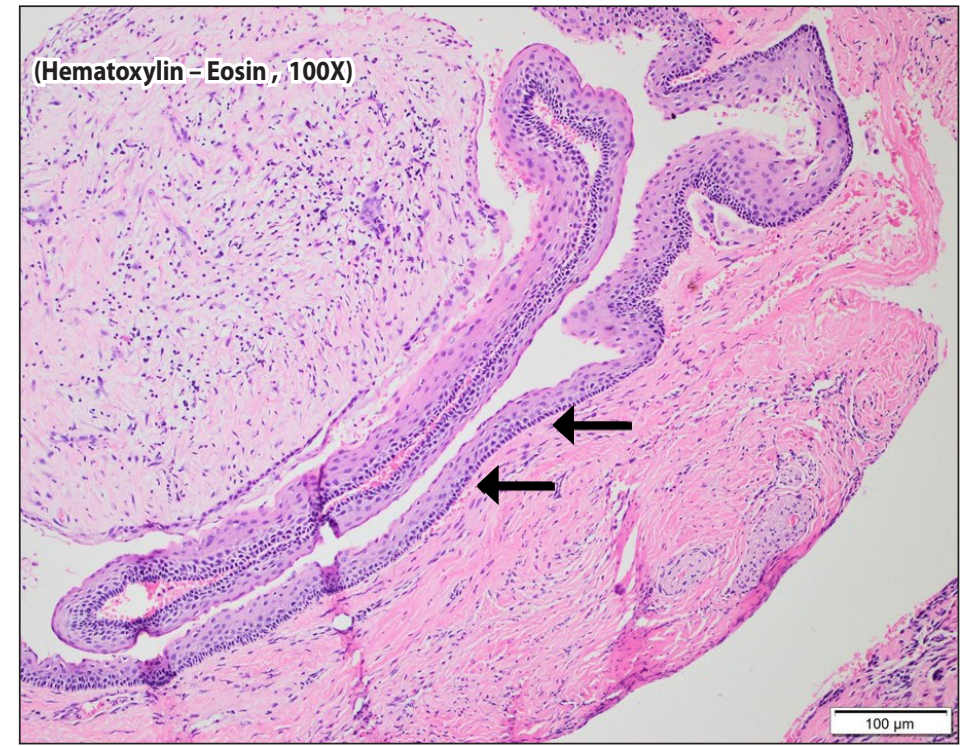

Figure 1. This section shows a fibrocollagenous cyst wall lined by a fairly thin and flat stratified squamous epithelium without rete ridges (arrows). (Hematoxylin-Eosin, 100X Magnification). 


\section{UNDER THE MICROSCOPE}

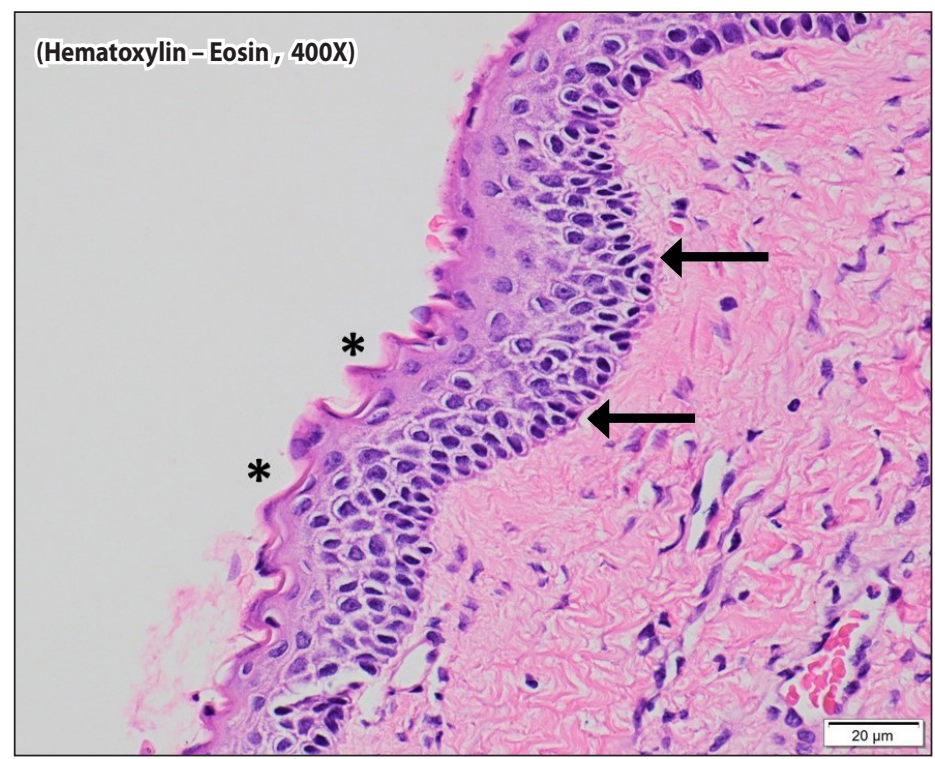

Figure 2. The epithelium is parakeratinized with a wavy, corrugated surface (asterisks) while the basal layer is cuboidal with hyperchromatic nuclei (arrows). (Hematoxylin-Eosin, 400X magnification).

Odontogenic keratocysts are the third most common cysts of the gnathic bones, comprising up to $11 \%$ of all odontogenic cysts, and most frequently occurring in the second to third decades of life. ${ }^{1,2}$ The vast majority of cases occur in the mandible particularly in the posterior segments of the body and the ramus. They typically present as fairly large unilocular radiolucencies with displacement of adjacent or overlying teeth. ${ }^{1}$ If associated with an impacted tooth the radiograph may mimic that of a dentigerous cyst. ${ }^{2}$

Microscopically, the parakeratinized epithelium without rete ridges, and with a corrugated luminal surface and a prominent cuboidal basal layer are distinctive features that enable recognition and diagnosis. ${ }^{1,2,3}$ Occasionally, smaller "satellite" or "daughter" cysts may be seen within the underlying supporting stroma, sometimes budding off from the basal layer. Most are unilocular although multilocular examples are encountered occasionally. ${ }^{1}$ Secondary inflammation may render these diagnostic features unrecognizable and non-specific. ${ }^{2}$

Morphologic differential diagnoses include other odontogenic cysts and unicystic ameloblastoma. The corrugated and parakeratinized epithelial surface is sufficiently consistent to allow recognition of an OKC over other odontogenic cysts, while the absence of a stellate reticulum and reverse nuclear polarization will not favor the latter diagnosis. $^{2,3}$

Odontogenic keratocysts are developmental in origin arising from remnants of the dental lamina. Mutations in the PTCH1 gene have been identified in cases associated with the naevoid basal cell carcinoma syndrome as well as in non-syndromic or sporadic cases. ${ }^{1,3}$ These genetic alterations were once the basis for proposing a neoplastic nature for OKCs and thus the nomenclature "keratocystic odontogenic tumor" was for a time adopted as the preferred name for the lesion., Presently, it is felt there is not yet enough evidence to support a neoplastic origin and hence the latest WHO classification reverts back to OKC as the appropriate term. ' Sekhar et al. gives a good review of the evolution of the nomenclature for this lesion. ${ }^{3}$

Treatments range from conservative enucleation to surgical resection via peripheral osteotomy. ${ }^{5}$ Reported recurrences vary in the literature ranging from less than $2 \%$ of resected cases up to $28 \%$ for conservatively managed cases. ${ }^{1,5}$ These are either ascribed to incomplete removal or to the previously mentioned satellite cysts - the latter being a feature associated with OKCs that are in the setting of the naevoid basal cell carcinoma syndrome. ${ }^{1,2,3}$ Thus, long term follow-up is recommended. ${ }^{5}$ Malignant transformation, though reported, is distinctly rare. ${ }^{2}$
REFERENCES

1. Speight P, Devilliers P, Li T-J, Odell EW, Wright JM. Odontogenic keratocyst. In: El-Naggar AK, Chan JKC, Grandis JR, Takata T, Slootweg PJ. WHO Classification of Head and Neck Tumors. Lyon: IARC; 2017. p. 235.

2. Neville BW, Damm DD, Allen CM. Odontogenic cysts and tumors. In: Gnepp DR (editor). Diagnostic Surgical Pathology of the Head and Neck. Philadelphia: Saunders/Elsevier; 2009. p. 790.

3. Sekhar MC, Thabusum DA, Charitha M, Chandrasekhar G, Shalini M. A review of the odontogenic keratocyst and report of a case. Journal of Advances in Medicine and Medical Research. 2019 Apr;29(8):1-7. DOI:10.9734/JAMMR/2019/v29i830107.

4. Philipsen HP. Keratocystic odontogenic tumor. In: Barnes L, Eveson JW, Reichart P, Sidransky D. World Health Organization Classification of Tumours. Pathology and Genetics of Head and Neck Tumors. Lyon: IARC; 2005. p.284.

5. Vallejo-Rosero KA, Camolesi GV, Duarte de Sá PL, Bernaola-Paredes WE. Conservative management of odontogenic keratocyst with long-term 5-year follow-up: Case report and literature review. Int I Surg Case Rep. 2020;66:8-15. DOI: 10.1016/j.jijscr.2019.11.023; PubMed PMID: 31785568; PubMed Central PMCID: PMC6889737. 